\title{
Distal monosomy 19p13.3
}

INSERM

\section{Source}

INSERM. (1999). Orphanet: an online rare disease and orphan drug data base. Distal monosomy 19p13.3. ORPHA:96129

Distal monosomy 19p13.3 is a rare chromosomal anomaly associated with a wide range of phenotypic features depending on the size of the deletion. It may present with intrauterine growth retardation, failure to thrive, global developmental delay, dysmorphic features (such as broad forehead, midface retrusion, broad nasal bridge, microg nathia, smooth philtrum, low-set, dysplastic ears), congenital anomalies (such as atrial septal defect, gastrointestinal anomalies, renal and urogenital malformations, agenesis of the corpus callosum) and other clinical features (such as hearing loss, visual impairment and immune dysregulation). 